\title{
Data Of Salivary Gland Adenoid Cystic And Muko-Epidermoid Carcınoma Patients
}

\section{Tükürük Bezi Adenoid Kistik Ve Muko-Epidermoid Kanserleri Hastalarımızın Verileri}

\author{
Fatih Demircioğlu', Beyhan Ceylaner Bıçakçı² \\ ${ }^{1}$ S.B.Ü. Dr. Alpaslan Yurtaslan Ankara Onkoloji Eğitim ve Araştırma Hastanesi, Radyasyon Onkolojisi Kliniği, \\ Ankara \\ ${ }^{2}$ S.B.Ü. Dr. Lütfi Kırdar Kartal Eğitim ve Araştırma Hastanesi, Radyasyon Onkolojisi Kliniği, İstanbul \\ Dergiye Ulaşma Tarihi: 20.12.2019 Dergiye Kabul Tarihi: 17.01.2020 Doi: 10.5505/aot.2020.24008
}

\section{ÖZET}

GİRIŞ ve AMAÇ: Tükürük bezi tümörleri, baş-boyun kanserlerinin yaklaşık \%3-5'ini oluşturan, farklı histolojik tiplere sahip heterojen bir kanser türüdür. Bu heterojenite ve görülme sıklıkları nedeni ile malign tükürük bezi tümörleri hakkında geniş serilerde araştırma makalesi bulunmamaktadır. Bu nedenle literatüre katkı sağlamak amacı ile Mukoepidermoid Karsinom (MEK) ve Adenoid Kistik Karsinom (AKK) tanılı hastalarımızın verileri çalışmada paylaşılmıştır.

YÖNTEM ve GEREÇLER: Temmuz 2007- Aralık 2018 tarihleri arasında tükrük bezi MEK ve AKK tanıları ile takip ve tedavileri yapılan 37 hasta çalışmaya dahil edildi. Hastaların patolojik tanıları, tümör lokalizasyonları, uygulanan tedaviler, lokal nüks varlığı, uzak metastaz varlığı ve sağ kalım süreleri retrospektif olarak değerlendirilerek ortalama veriler incelendi.

BULGULAR: Çalışmaya dahil edilen hastaların 14'ü MEK, 23'ü AKK idi. Ortalama yaş 50,15'di. AKK'lı hastaların yaş ortalaması daha fazlaydı $(52,77$ - 45,84). Tüm hastaların 16'sı parotis, 8'i submandibuler, 13'ü ise sublingual ve minör tükürük bezleri yerleşimliydi. MEK'li \%14,3, AKK'l1 \%13 hastada lokal nüks izlenirken, MEK'da \%7,1, AKK'da \%34,8 uzak metastaz saptandı. MEK'li hastalarda ortalama sağ kalım süresi 71,2 ay olarak hesaplanırken bu süre AKK'da 56,4 aydı.

TARTIŞMA ve SONUÇ: Çalışmamızda elde ettiğimiz veriler, genel olarak güncel literatür ile uyumlu bulunmuştur. Nadir görülen bu hastalık grubunda literatür verilerine katkı sağlandığı düşünülmektedir. Takip ve tedavi standardizasyonu amacı ile çok merkezli randomize klinik çalışmalara ihtiyaç vardır.

Anahtar Kelimeler: Tükürük bezi, Mukoepidermoid Kanser, Adenoid kistik kanser, Radyoterapi

\section{ABSTRACT}

INTRODUCTION: Salivary gland tumors are a heterogeneous type of cancer with different histological types, accounting for approximately 3-5\% of head and neck cancers. Due to this heterogeneity and its incidence, there are no research articles about malignant salivary gland tumors in large series. Therefore, in order to contribute to the literature, the data of our patients with Mucoepidermoid Carcinoma (MEC) and Adenoid Cystic Carcinoma (ACC) were shared in the study.

METHODS: Thirty-seven patients with salivary gland MEC and ACC between July 2007 and December 2018 were included in the study. Pathological diagnoses, tumor localizations, treatments, presence of local recurrence and distant metastasis and survival were evaluated retrospectively and mean data were analyzed. RESULTS: Of the patients included in the study, 14 were MEC and 23 were ACC. The mean age was 50.15. The mean age of patients with ACC was higher (52.77 - 45.84). Tumor localization of all patients; 16 were parotid, 8 were submandibular, 13 were sublingual and minor salivary glands. Local recurrence was observed in $14.3 \%$ of MEC and $13 \%$ of ACC patients. Distant metastasis were seen in $7.1 \%$ of MEC and $34.8 \%$ of ACC patients. The mean survival time was 71.2 months in patients with MEC, and 56.4 months in ACC. DISCUSSION AND CONCLUSION: The data we obtained in our study were generally consistent with the current literature. It is thought to contribute to the literature data in this rare group of diseases. Multicentre randomized clinical trials are needed for follow-up and treatment standardization.

Keywords: Salivary gland, Mucoepidermoid carcinoma, Adenoid cystic carcinoma, Radiotherapy 


\section{GíRIS}

Tükürük bezi tümörleri, baş-boyun kanserlerinin yaklaşık \%3-5'ini oluşturan, farklı histolojik tiplere sahip heterojen bir kanser türüdür $(1,2)$. Çoğu benign histolojide olmakla birlikte en sik görülen malign histolojiler Mukoepidermoid Karsinom (MEK) ve Adenoid Kistik Karsinom (AKK)'dur $(3,4)$. Tüm tükürük bezi tümörlerinin yaklaşı \% $\% 14$ 'ü MEK, \%12'si AKK'dır $(5,6)$.

Tükürük bezi tümörlü hastalarda ana semptom bölgesel şişliktir (7). Lokalize ve rezektabl tümörlerde, cerrahi ve sonrasında gerekli hastalara radyoterapi, ana tedavi yöntemidir (8).

$\mathrm{Bu}$ heterojenite ve görülme s1klıkları nedeni ile malign tükürük bezi tümörleri hakkında geniş serilerde araştırma makalesi bulunmamaktadır. $\mathrm{Bu}$ doğrultuda literatüre katkı sağlamak amacı ile çalışmamızda, en sık malign tükürük bezi tümörleri olan MEK ve AKK hastalarımızın verileri ve tedavi sonuçları paylaşılmıştır $(9,10)$.

\section{GEREÇ VE YÖNTEM}

Çalışmaya, kliniğimizde Temmuz 2007- Aralık 2018 tarihleri arasında tükrük bezi MEK ve AKK tanıları ile takip ve tedavileri yapılan 37 hasta dahil edildi. Hastaların 14'ü MEK, 23'ü AKK'du. 21 hasta kadın, 16 hasta erkekdi. Tüm hastaların yaş ortalamaları 50,15'di (16,3$82,1)$.

Hastaların patolojik tanıları, tümör lokalizasyonlar1, uygulanan tedaviler, lokal nüks varlığ 1 , uzak metastaz varlı̆̆ 1 ve sağ kalım süreleri retrospektif olarak değerlendirildi. İstatistiki değerlendirmede numerik değerler ve sağ kalım süreleri SPSS versiyon 15 'de descriptive analiz yapılarak ortalama değer olarak sunuldu.

Retrospektif olarak yapılan çalışmamız için hastanemiz Tıpta Uzmanlık Eğitim Kurulu (TUEK) onayı alınmıştır.

\section{SONUÇLAR}

Çalışmaya dahil edilen hastaların 14'ü MEK, 23'ü AKK idi. MEK tanılı hastaların 8'i kadın, 6's1 erkek; AKK tanılı hastaların 13'ü kadın 10 'u erkekdi. AKK'lı hastaların yaş ortalaması
$(52,77)$ MEK tanılı hastalardan $(45,84)$ daha fazlaydi.

Tümör yerleşim yerleri değerlendirildiğinde tüm hastaların 16's1 parotis, 8'i submandibuler, 13'ü ise sublingual ve minör tükürük bezleri yerleşimliydi. Tanılara göre tümör yerleşim yerleri tablo l'de verilmiştir.

Tablo 1: Histopatolojik tanılara göre tümör yerleşim yerleri.

\begin{tabular}{|l|c|c|c|c|}
\hline & Parotis & $\begin{array}{c}\text { Submand } \\
\text { ibuler }\end{array}$ & Sublingual & Minör \\
\hline $\begin{array}{l}\text { Mukoepidermoid } \\
\text { Karsinom }\end{array}$ & $\begin{array}{c}10 \\
(\% 71,4)\end{array}$ & 0 & 0 & $\begin{array}{c}4 \\
(\% 28,6)\end{array}$ \\
\hline $\begin{array}{l}\text { Adenoid Kistik } \\
\text { Karsinom }\end{array}$ & $\begin{array}{c}6 \\
(\% 26,1)\end{array}$ & $\begin{array}{c}8 \\
(\% 34,8)\end{array}$ & $5(\% 21,7)$ & $\begin{array}{c}4 \\
(\% 17,4)\end{array}$ \\
\hline
\end{tabular}

astaların 20'sine adjuvan radyoterap uygulanmad. MEK 17 hastaya RT uygulanmadi. MEK tanılı 14 hastanın 5'ine $(\% 35,7)$, AKK tanılı 23 hastanın 15'ine $(\% 65,2)$ RT uygulandi. Radyoterapi almayan 5 hastanın metastatik hastalığ 1 olduğu için adjuvan tedavi endikasyonu konulmadı. Cerrahi uygulamaları açısından bakıldığında hastalarm 20'sine $(\% 54,1)$ total parotidektomi uygulanırken 17 'sine $(\% 45,9)$ parsiyel parotidektomi uygulanmıştır.

Lokal nüks ve uzak metastaz değerlendirilmesinde; MEK'li 2 hastada $(\% 14,3), A^{\prime} K^{\prime} 113$ hastada (\%13) lokal nüks izlenirken, MEK'li 1 hastada (\%7,1), AKK'l1 8 hastada $(\% 34,8)$ uzak metastaz saptand.

Çalışma dahilindeki tüm hastaların ortalama sağ kalım süreleri 62 ay (4-149) olarak hesaplandi. MEK'li hastalarda bu süre 71,2 ay (4-149) idi. AKK'lı hastalarda MEK'li hastalara göre daha düşük sağ kalım oranları saptandı. AKK'da ortalama sağ kalım süresi 56,4 ay (5-141) şeklinde bulundu.

\section{TARTIŞMA}

Çalışmamızda tükürük bezinin en sık malign tümörleri olan MEK ve AKK verilerimiz incelenmiştir ve nadir görülen ve histolojik olarak çok heterojen olan bu grup hastalıkta ulusal anlamda veri bankasina katk1 sağlayacağı düşünülmüştür $(9,10)$. Tükürük bezi tümörleri genel olarak kadın hastalarda daha s1k izlenmektedir. Malign tükürük bezi tümörlerinde de bu oran benzerdir $(11,12)$. Fakat ülkemizde yayınlanmış bazı makalelerde 
tükürük bezi tümörlerinin erkerlerde daha yüksek oranda görüldüğü gösterilmiştir $(13,14)$. Bizim verilerimizde tüm hasta grubunun yaklaşı \%57'si kadındır. Hastalar histolojik olarak ayrıldıklarında da benzer oranlar elde edilmiştir. $\mathrm{Bu}$ oranların uluslararası verilerle uyumlu olduğu saptanmıştır.

Tümör yerleşim yerleri değerlendirildiğinde genel olarak en sik, en büyük tükürük bezi olan parotis bezinde tümöral oluşum izlenmektedir (15). Bu oranlar histolojik olarak MEC ve AKK ayrımı yapıldığında farklılık göstermektedir. MEC daha çok parotis bezinde izlenirken AKK en sık submandibuler ve minör tükürük bezlerinde görülmektedir (16,17). Çalışmamızda da MEK'lu 14 hastanın 10'unda parotis yerleşimi, kalan 4 hastada minör tükürük bezi yerleşimi gözlenmiştir. AKK'da ise daha heterojen bir dağ 11 m vardır. 8 hastada submandibuler bez, 6 hastada parotis bezi, 5 hastada sublingual bez ve 4 hastada minör tükürük bezi yerleşimi saptanmıştır.

Malign tükürük bezi tümörleri tedavisinin ana modaliteleri cerrahi ve sonrasında lokal nüks açısından yüksek riskli hastalarda ve özellikle AKK histolojisinde adjuvan postoperatif radyoterapidir (18-20). Literatürümüzdeki hasta serilerinde de adjuvan RT hastaların yarısından fazlasina uygulanmıştır. AKK histolojisinde bu oran $\% 65,2$ 'dir. Tümör histolojilerine baktığımızda çalışmamızda AKK'lu hastalar daha fazladır. Bunun nedeninin, çalışmanın radyasyon onkolojisinde takipli hastalar üzerinde yapılmış olduğu düşünülmektedir. Ayrıca ülkemizde yapılan bazı çalışmalarda da malign tümörler içinde AKK histolojisinin daha sık izlendiği çalışmalar bulunmaktadır (21).

Lokal nüks ve uzak metastaz açısından malign tükürük bezi tümörlerinin değerlendirildiği çalışmalarda ve derlemelerde MEK'da daha çok lokal nüks izlenirken AKK'da yüksek uzak metastaz oranları saptanmıştır $(15,16,18,20)$. Çalışmamızda da güncel bilgilere benzer şekilde AKK tanılı 8 hastada $(\% 34,8)$ uzak metastaz gözlenmiştir. MEK'da ise 1 hastada uzak metastaz olup bu oran $\% 7,1$ 'dir.

Çalışmamızda MEK'da AKK'a göre daha yüksek oranda sağ kalım verileri elde edilmiştir. Veriler mevcut literatür ile uyumludur. $\mathrm{Bu}$ fark, $\mathrm{AKK}$ 'da daha yüksek oranda uzak metastaz oranlarının olması ile ilişkilidir (22).

Çalışmamızın eksik yönleri, hastaların retrospektif değerlendirilmesi ve evreleme kriterleri ve uygulanan cerrahi yöntemlere göre ayrıntılı sağ kalım analizlerinin yapılmamış olmasıdır.

Nadir görülen bir tümör grubu olan tükürük bezi MEK ve AKK tanısıyla takip edilen hastalarımızın değerlendirildiği bu çalışmamızda elde ettiğimiz veriler, genel olarak güncel literatür ile uyumlu bulunmuştur. Hastaların daha etkin kategorize edilebilmesi ve tedavi standardizasyonun daha iyi yapılabilmesi amacı ile çok merkezli, daha fazla hasta sayısı ile ve tüm prognostik faktörlerin dahil edildiği, ayrıntılı sağ kalım analizlerinin yapıldı $\breve{g}_{1}$ randomize klinik çalışmalara ihtiyaç vardır.

\section{REFERANSLAR}

1. Carvalho AL, Nishimoto IN, Califano JA, Kowalski LP. Trends in incidence and prognosis for head and neck cancer in the United States: a site-specific analysis of the SEER database. Int $\mathrm{J}$ Cancer 2005;114:806-16.

2. BoukherisH, Curtis RE, Land CE, et al: Incidence of carcinoma of the major salivary glands according to the WHOclassification, 1992 to 2006: A populationbased study in the United States. Cancer Epidemiol Biomarkers Prev 2009;18: 2899-906.

3. Sentani K, Ogawa I, Ozasa K, Sadakane A, Utada M, Tsuya T. Characteristics of 5015 Salivary Gland Neoplasms Registered in the Hiroshima Tumor Tissue Registry over a Period of 39 Years. J Clin Med. 2019;8:566.

4. Ito FA, Ito K, Vargas PA, de Almeida OP, Lopes MA. Salivary gland tumors in a Brazilian population: a retrospective study of 496 cases. Int J Oral Maxillofac Surg. 2005;34:533-6.

5. Fitzpatrick PJ, Theriault C. Malignant salivary gland tumors. Int J Radiat Oncol Biol Phys 1986;12:17437.

6. Alper M., Patıroğlu T.E., Belenli O. Tükrük Bezi Tümörleri: 142 Olgunun Histopatolojik Tip, Yerleşim Yeri, Yaş ve Cinsiyet Dağılım Analizi. Turkjpat. 2001;17(1-2):18-20.

7. Przewozny T, Stankiewicz C. Neoplasms of the parotid gland in northern Poland, 1991-2000: an epidemiologic study. Eur Arch Otorhinolaringol 2004;261:369-75.

8. Sood S, McGurk M, Vaz F. Management of salivary gland tumours: United Kingdom national multidisciplinary guidelines. J Laryngol Otol 2016;130:142-9.

9. Zaman S, Majid S, Chugtai O, Hussain M, Nasir M. Salivary gland tumours: a review of 91 cases. J Ayub Med Coll Abbottabad. 2014;26(3):361-3.

10. Trenkić Božinović M, Krasić D, Katić V, Krstić M. A retrospective review of 139 major and minor 
salivary gland tumors. Med Glas (Zenica). 2015;12(1):73-8.

11. Guintinas-Lichius O, Klussmann JP, Wittekindt C, Stennert E. Parotidectomy for benign parotid disease at a university teaching hospital: outcome of 963 operations. Laryngoscope 2006;116:534-40.

12. Galdirs TM, Kappler M, Reich W, Eckert AW. Current aspects of salivary gland tumors a systematic review of the literature. GMS Interdiscip Plast Reconstr Surg DGPW. 2019;8:Doc12. doi: 10.3205/iprs000138. eCollection 2019.

13. Topak M, Çelebi Ş, Develioğlu ON, ve ark. Parotis kitlelerinde tani ve tedavi sonuçlarimiz. Selçuk Tıp Derg 2013;29:64-67.

14. Akın İ, Günen A, Gürzumar A, et al. Parotis tümörlerine tedavi yaklaşımımız. K.B.B. ve Baş Boyun Cerrahisi Dergisi 1994;2:38-42.

15. Reinheimer A, Vieira DS, Cordeiro MM, Rivero ER. Retrospective study of 124 cases of salivary gland tumors and literature review. J Clin Exp Dent. 2019;11(11):e1025-e1032. doi: 10.4317/jced.55685. eCollection 2019 Nov.

16. Dubergé T, Bénézery K, Resbeut M, et al. [Adenoid cystic carcinoma of the head and neck: a retrospective series of 169 cases]. Cancer Radiother. 2012;16(4):247-56. doi: 10.1016/j.canrad.2012.02.003. Epub 2012 May 29.
17. Yan K, Yesensky J, Hasina R, Agrawal N. Genomics of mucoepidermoid and adenoid cystic carcinomas. Laryngoscope Investig Otolaryngol. 2018;3(1):56-61. 10.1002/lio2.139. eCollection Feb.

18. Son E, Panwar A, Mosher C.H, Lydiatt D. Cancers of the Major Salivary Gland. Journal of Oncology Practice. 2018;14:2. DOI: https://doi.org/10.1200/JOP. 2017.026856

19. Garg M, Tudor-Green B, Bisase B. Current thinking in the management of adenoid cystic carcinoma of the head and neck. Br J Oral Maxillofac Surg. 2019;57(8):716-21. doi: 10.1016/j.bjoms.2019.07.021. Epub 2019 Aug 14.

20. David B. Shultz D.B, Zeidan Y.H, Murphy J.D, et al. Radiotherapy for adenoid cystic carcinomas of the head and neck: clinical outcomes and patterns of failure. Journal of Radiation Oncology. 2014;33:4956.

21. Özbay M, Şengül E, Topçu İ. Parotis Kitlelerinde Tanı ve Cerrahi Tedavi Sonuçları. Dicle Medical Journal. 2016;43(2):315-8. doi: 10.5798/diclemedj.0921.2016.02.0688

22. Martins-Andrade B, Dos Santos Costa SF, Sant'ana MSP, et al. Prognostic importance of the lymphovascular invasion in head and neck adeno idcystic carcinoma:A systematic review and meta analysis. Oral Oncol. 2019;93:52-8. doi: 10.1016/j.oraloncology.2019.04.014. Epub 2019 Apr 24. 